\title{
ESTIMATES FOR NEUMAN-SÁNDOR MEAN BY POWER MEANS AND THEIR RELATIVE ERRORS
}

\section{ZHEN-HANG YANG}

Abstract. For $a, b>0$ with $a \neq b$, let $N S(a, b)$ denote the Neuman-Sándor mean defined by

$$
N S(a, b)=\frac{a-b}{2 \operatorname{arcsinh} \frac{a-b}{a+b}}
$$

and $A_{p}(a, b), \mathscr{L}_{p}(a, b)$ denote the $r$-order power and Lehmer means. Based on our earlier worker [27], we prove that

$$
\alpha_{p} A_{p}<N S<A_{p} \text { and } A_{p}<N S \leqslant \beta_{p} A_{p}
$$

holds if and only if $p \geqslant 4 / 3$ and $p \leqslant p_{0}$, respectively, where

$$
\begin{aligned}
& \alpha_{p}=\left(2^{1 / p-1}\right) / \ln (1+\sqrt{2}) \text { if } p \in[1 / 4 / 3, \infty), \\
& \beta_{p}= \begin{cases}N S\left(1, x_{0}\right) / A_{p}\left(1, x_{0}\right) & \text { if } p \in\left(1, p_{0}\right], \\
2^{1 / p-1} / \ln (1+\sqrt{2}) & \text { if } p \in(0,1], \\
\infty & \text { if } p \in(-\infty, 0]\end{cases}
\end{aligned}
$$

are the best constants, here $x_{0}$ is the unique root of the equation

$$
N S(1, x)=\frac{A(1, x) A_{2}(1, x)}{\mathscr{L}_{p_{0}-1}(1, x)}
$$

on $(0,1)$, and $p \mapsto \alpha_{p} A_{p}$ is decreasing on $(0, \infty)$. Also, we have

$$
\alpha_{4 / 3} A_{4 / 3}<A_{p_{0}}<N S<A_{4 / 3}<\alpha_{4 / 3}^{-1} A_{p_{0}} .
$$

Our results clearly are generations of known ones.

Mathematics subject classification (2010): 26E60, 26D05.

Keywords and phrases: Neuman-Sandor mean, power mean, Lehmer mean, inequality, relative error.

\section{REFERENCES}

[1] P. S. Bullen, D. S. Mitrinović And P. M. Vasić, Means and Their Inequalities Dordrecht, 1988.

[2] Y.-M. ChU, AND B.-Y. Long, Bounds of the Neuman-Sándor mean using power and identric means, Abstr. Appl. Anal. 2013 (2013), Art. ID 832591, 6 pages, http://dx.doi.org/10.1155/2013/ 832591.

[3] Y.-M. Chu, B.-Y. Long, W.-M. Gong AND Y.-Q. Song, Sharp bounds for Seiffert and NeumanSándor means in terms of generalized logarithmic means, J. Inequal. Appl. 2013, 2013:10; available online at http://www . journal of inequalitiesandapplications . com/content/2013/1/10.

[4] I. Costin And G. ToAder, Optimal evaluations of some Seiffert-type means by power means, Appl. Math. Comp. 219 (2013), 4745-4754; available online at http://dx.doi.org/10.1016/ j.amc.2012.10.091.

[5] I. COSTIN AND G. TOADER, A nice separation of some Seiffert type means by power means, Int. J. of Math. Math. Sci, 2012, (2012), Art. ID 430692, 6 pages, doi : 10.1155/2012/430692. 
[6] P. A. HÄstö, A monotonicity property of ratios of symmetric homogeneous means, J. Inequal. Pure Appl. Math. 3, 5 (2002), Art. 71, 23 pp.

[7] P. A. Hësтö, Optimal inequalities between Seiffert's mean and power mean, Math. Inequal. Appl. 7, 1 (2004), 47-53.

[8] A. A. JAGERS, Solution of problem 887, Nieuw Arch. Wisk. 12 (1994), 230-231.

[9] D. H. LeHMER, On the compunding of certain means, J. Math. Anal. Appl. 36 (1971), 183-200.

[10] Y.-M. Li, B.-Y. Long AND Y.-M. ChU, Sharp bounds for the Neuman-Sádor mean in terms of generalized logarithmic mean, J. Math. Inequal. 6, 4 (2012), 567-577.

[11] T. P. Lin, The power mean and the logarithmic mean, Amer. Math. Monthly 81 (1974), 879-883.

[12] E. Neuman AND J. SÁNDOR, ON certain means of two arguments and their extensions, Intern. J. Math. Math. Sci. 2003, 16 (2003), 981-993.

[13] E. Neuman And J. SÁndor, On the Schwab-Borchardt mean, Math. Pannon. 17, 1 (2006) 49-59.

[14] E. Neuman, A note on a certain bivariate mean, J. Math. Inequal. 6, 4 (2012), 637-643.

[15] A. O. Pittinger, Inequalities between arithmetic and logarithmic means, Univ. Beogard Publ. Elektr. Fak. Ser. Mat. Fiz, 680 (1980), 15-18.

[16] H.-J. SEIFFERT, Werte zwischen dem geometrischen und dem arithmetischen Mittel zweier Zahlen, Elem. Math. 42 (1987), 105-107.

[17] H.-J. SeIfFerT, Problem 887, Nieuw Arch. Wisk. 4, 11 (1993), 176.

[18] H.-J. SEIFFERT, Aufgabe 16, Die Wurzel 29 (1995), 221-222.

[19] K. B. Stolars Ky, Generalizations of the Logarithmic Mean, Math. Mag. 48 (1975), 87-92.

[20] K. B. Stolars Ky, The power and generalized logarithmic means, Amer. Math. Monthly 87 (1980), $545-548$.

[21] M.-K. WANG, Y.-M. ChU AND B.-Y. LiU, Sharp inequalities for the Neuman-Sandor mean in terms of arithmetic and contra-harmonic means, 2012; available online at http://arxiv.org/pdf/ 1209.5825.pdf.

[22] ZH.-H. YANG, On the monotonicity and log-convexity for one-parameter homogeneous functions, RGMIA Res. Rep. Coll. 8, 2 (2005), Art. 14,; available online at http://rgmia.vu.edu.au/ v8n2.html.

[23] ZH.-H. YANG, ON the log-convexity of two-parameter homogeneous functions, Math. Inequal. Appl. 10, 3 (2007), 499-516.

[24] ZH.-H. YANG, Some monotonictiy results for the ratio of two-parameter symmetric homogeneous functions, Int. J. Math. Math. Sci. 2009, Art. ID 591382, 12 pages, 2009. doi:10.1155/2009/ 591382; available online at http://www.hindawi.com/journals/ijmms/2009/591382.html.

[25] ZH.-H. YANG, Log-convexity of ratio of the two-parameter symmetric homogeneous functions and an application, J. Inequal. Spec. Func. 1, 1 (2010), 16-29; available online at http://www.ilirias. com.

[26] ZH.-H. YANG, Sharp bounds for the second Seiffert mean in terms of power means, 2012; available online at http://arxiv.org/pdf/1206.5494v1.pdf.

[27] ZH.-H. YANG, Sharp power means bounds for Neuman-Sádor mean, 2012; available online at http://arxiv.org/abs/1208.0895.

[28] ZH.-H. YANG, The monotonicity results and sharp inequalities for some power-type means of two arguments, 2012; available online at http://arxiv. org/pdf/1210.6478.pdf.

[29] T.-H. ZhaO, Y.-M. ChU AND B.-Y. LiU, Optimal bounds for Neuman-Sándor mean in terms of the convex combinations of harmonic, geometric, quadratic, and contraharmonic means, Abstr. Appl. Anal. 2012 (2012), Art. ID 302635, 9 pages, doi : 10.1155/2012/302635. 